\title{
UM BREVE ESTUDO: da pré-comunicação à comunicação midiática
}

\author{
A n objective study: from the precommunication to the media communication
}

\begin{abstract}
Michele César Farah
Mestranda em Comunicação e Cultura pela UNISO, Professora da Faculdade Anhanguera de Sorocaba nos cursos de Administração, Publicidadee Pós-G raduação lato sensu, Sorocaba, SP - Brasil, e-mail: michele.farah@ gmail.com
\end{abstract}

\section{Resumo}

Este ensaio anseia apresentar algumas considerações sobre a comunicação, não só como teoria, mas, em especial, como processo evolutivo do homem enquanto espécie e ser social. Logo, temos como concepção a força que a palavra possui, tanto como signo quanto como capacidade de desenvolvimento da raça humana. A ssim, nosso objetivo aclara-se, já que oferecemos a compreensão de temas como a pré-comunicação, a incomunicabilidade e 0 advento das formas mediadas de comunicação.

Para atingir nosso propósito neste estudo, faremos uso de três análises. Primeiramente, a pré-comunicação por meio do estudo do prólogo do filme 2001 - U ma 0 disséía no E spaço e, posteriormente, com 0 conto ficcional Berom, abordaremos a questão do poder da palavra enquanto forma de relacionar os seres, bem como as consequências desta força para a manipulação do conhecimento para o interesse ideológico-político. Por fim, no filme de Robert Altman - Short C uts - iremos compreender os adventos das mídias, bem como a forma de reorganização que o homem, enquanto ser social, passou a adotar em seu cotidiano, mesmo que pense que suas ações sejam isoladas, ou seja, percebemos que nossas vidas estão extremamente aliadas aos movimentos midiáticos, que hoje nos envolvem.

Palavras-chave: Pré-comunicação; Poder da palavra; Manipulação; Comunicação midiática.

\begin{abstract}
This essay presents some concepts about the communication, not only as theory, but, in special, as the evolution process of the man while human being and its social behavior. Therefore, we have as conception the force that the word possesses, as a sign and as the capacity of development of the human being.

Thus, our objective clears up itself, since it offers the understanding of subjects as the precommunication, the incommunicability and the advent of the mediated forms of communication. To reach our intention in this study, we will make use of three analyses.
\end{abstract}


First, pre-communication by means of the study of the prologue of the film 2001 - Odyssey and, later, next to the fictional story Berom, we will approach the question of the power of the word, while it forms to relate the beings, as well as the consequences of this force for the manipulation of the knowledge for ideological-politician benefit. Finally, in the film of Robert Altman Short Cuts we will understand the increase of the medias, as well as the reorganization form that man, as social individuals, started to adopt in its day-by-day, even thinking that its action is isolated, but perceiving that our lives are extremely allied to the medias movements, that nowadays involves us.

Keywords: Pre-communication; Power of word; Manipulation; Media communication.

\section{PRÉ-COMUNICAÇÃO}

[...] o que especifica o homem no seu longo caminhar das trevas até a luz, no seu arrancar-se à animalidade, é que este grito lhe abre a porta da palavra articulada, logo se dá comunicação inter-individual e, por fim, todas as que dele dependem e que comandam a história das técnicas e a nossa própria história. (MAURICE FABRE, 1980, p. 8-9).

\section{INTRODUÇÃO}

Diante dos mais diversos estudos realizados sobre linguagem, desde Luria, Vygotsky, Bakhtin aos estudos de recepção ou a escola de Frankfurt, além da semiótica, observamos que 0 homem encontra na palavra sua plenitude para ter e compartilhar conhecimento. Esses dois pontos advêm do próprio logos grego, o qual envolve amplamente 0 saber e o expressar. Para tanto, esse ensaio versa sobre os caminhos que a comunicação, enquanto emancipação humana, percorreu para se encontrar no constante advento dos meios de comunicação, ou seja, iremos analisar alguns fatores que auxiliaram no avanço da linguagem humana, o qual se tornou, hoje, dependente das produções midiáticas para adquirir informações embebidas de imposições pragmáticas, as quais são advindas do próprio desenvolvimento exacerbado do capitalismo e da tecnociência. ${ }^{1}$
Vale ressaltar que não se trata de um ensaio sobre todas as linhas de estudo sobre linguagem, mas sim de uma interpretação da evolução destapelo uso deprodutos decomunicação: texto efilme. Logo, nosso objetivo é apresentar, por meio da análise de um conto ficcional e duas películas, dos quais podemos compreender a evolução dalinguagem e sua impregnação midiática, que tiveram influências iniciais nas transformações ocorridasnos séculos XVII eXVIII, tanto no âmbito da economia quanto política, bem como social.

\section{Princípio}

A Aurora nos oferece o cântico da vida, ou seja, está relacionada às melhores transformações do ser, tanto espiritual quanto física. Observamos este envolvimento no "Conto da Serpente Verde" de $\mathrm{G}$ oethe ${ }^{2}$, em que tudo e todos tendem para a luz, símbolo de perfeição e de acabamento.

\footnotetext{
1 [...]paraa tecnociência contemporânea não hátal inconsciente, mas apenas sistemas deprocessamento deinformação. 0 homem é pensado como um sistema complexo de pro cessamento de informação dentre outros. 0 potencial da tecnologia ultrapassa a estrita referência à condição humana, po ssibilitando novas criaçõ es que apontam para a superação das limitações próprias ao orgânico. FERRAZ, MariaCristina. Sociedade tecnoló gica: de Prometeu aFausto. UNISINO S, 1998. D isponível em: <http:/ / www.comunica.unisinos.br/ tics/ textos/ 1998/ 1998_mcff.pdf>. Acesso em: 02 out. 2008.

20 "Conto da SerpenteV erde" éumaalegoria da transformação. Cada personagem sem exceção étransformado ou transmutado e passa a um estado mais elevado, mais positivo ou mais útil. D e um estado de potencialidade latente, as figuras arquetípicas evolvem para um modo de ser mais equilibrado, completo estável.
} 
Ora, ao apreciar uma das maiores obras do cinema, "2001 - Uma Odisséia no Espaço", sentimos em seu prólogo esta mesma essência iluminada pelos seus efeitos visuais. Trata-se de uma "voz" diferente que nos sublima aos dois princípios fundadores: criação e evolução. Contemplamos o diálogo das forças do Universo, bem como suasimpulsões motivadoras econdutoras do comportamento humano.

D estaforma, podemoscompreender, pelas vias do cinema, como ocorre a pré-comunicação. Este filme é um convite ao entendimento deste processo, tal qual uma alusão aos primórdios do relacionamento e expressão humanos, mesmo que representados pela figura do "hominídio".

Sendo assim, à luz da "A urora do Homem", Stanley Kubrick e Arthur Clarke transmitem 0 "ver, como se o espectador estivesse nu diante do cosmo, o saber. Q uem vê, tem poder." (Nei D uclós ${ }^{3}$ ). Todo este olhar ocorre sob o silêncio implícito do "espírito de D eus" que paira sobre a criação. Há alguns efeitos sonoros pincelados com sutileza e astúcia pela maestria do diretor.

\section{Criar e evoluir, evoluir e criar}

Ao desenvolver as cenas, passamos por períodos, desde proclamar o mundo até a invenção da ferramenta e arma. A princípio, podemos compreender que a convivência era pacífica, mas também fluía por meio de grunhidos e gestos exacerbados com a finalidade de transmitir algo instintivo, sem reflexão. Ademais, nossos semelhantes eram herbívoros e lutavam pela água com os outros grupos, pois esta era o "bem maior".

Sendo assim, abrimos um espaço para comentar a realidade atual e nada ficcional, em que a água é fonte de vida, todavia percebemos sua findável existência em algumas décadas. Nesta película, notamos sua importância a partir de nossos primórdios. 0 que há por vir é, no mínimo, extremamente preocupante.

Remetemos, também, aos medosinerentes a nossa natureza. Escuridão, ausência de luz, solidão, necessidade de proteção, refúgio. Todos estes aspectos demonstrados pelos olhares dos personagens deste prólogo, os quais apontam a noção de um perigo real ou imaginário, de uma ameaça, pavor, temor. Até hoje, somos atingidos por estes terrores.

Frente ao desconhecido, a mistura de sensações e percepções é colocada sem palavras pelos hominídios - toques, grunhidos, olhares temerosos e admirados. Mais um passo é dado. Um contato com a revelação, isto é, a obra perfeita de um só bloco de pedra, estela, marco. Neste momento, Kubrick e Clarke adicionam a música de Strauss, tal qual o signo do sagrado em adoração e denotação do nascimento do Cosmo, bem como o advento de uma força maior, a qual atua de modo místico.

Outro momento de evolução. O personagem encontravestígiosósseos deum animal, que provavelmente fora devorado pelo Felino figura de domínio, a qual surge rapidamente em duas cenas. Assim, os movimentos de batidas, grunhidos e gestos de força impulsionam o próximo passo: a detenção de um poder de matar na luta pela sobrevivência.

A partir desta cena, tornam-se carnívoros e lutam entre si para ganhar a água e proteção. No clímax deste prólogo, a criatura confronta-se com 0 fundamento da evolução: subjugar para sobreviver em melhores condições e alcançar a dominância.

D esta maneira, a pré-comunicação ocorre pelo ato de alçar o osso junto aos grunhidos e gestos como "cantos de vitória", quando matam outro de mesma espécie, remetendo à ostentação do poder sob os demais. Pelo olhar de orgulho, de vitória. Pela algazarra e pelo clamor. É lançado ao céu (= simbologia do grande Criador) a primeira máquina simples - um corpo rígido capaz de girar em volta de um fulcro, no qual se estabelece um equilíbrio de momentos pela ação de duas forças: a potência e a resistência.

Assim, as cenas deste prólogo culminam dentro de uma nave espacial, onde um passageiro dorme e sua caneta desprende de seu bolso, passeando pela tela em primeiro plano, graças à ausência de gravidade, e a genialidade do diretor, que sem o uso de palavras, nos apresenta um dos maiores símbolos da comunicação: a escrita.

\section{0 olhar. 0 convite}

Kubrick, o cineasta da libertação do olhar. Para saber, é preciso ver o que não foi

\footnotetext{
Escritor ejornalista, autor de Universo baldio (romance, Francis) e No mar, veremos (poesia, G lobo), entre outros.
} 
ainda codificado. Codificar não é saber, essa já é uma fase posterior ao saber. Em suma, saber não é compreender, é enxergar. 0 que você vê é o que você conhece. G odard disse: vejam, vocês estão vendo, aprendam a ver. Kubrick não é didático. Kubrick diz: veja só, um retângulo escuro e alto que emite um ruído eaparece no meio dos macacos e depois enterrado na Lua. Trata-se da única prova viva de que o Tempo existe como percepção e jamais como barreira. Kubrick vislumbrou sua saga no momento em que se evadiu da sua época e decidiu visitar o Mistério.

Desde modo perspicaz, "2001 - Uma O disséia no Espaço" contempla em seu prólogo elementos formadores de um espectro de alusões fundadas no movimento anterior à comunicação e seu "logos". O olhar do Hominídio é extremamente representativo e sua semelhança é percebida hoje em nossa vida, pois há quem diga que os olhos são espelhos da alma. Por eles, recebemos e transmitimos muito do que somos, sentimos e instintivamente desejamos.

A Aurora do Homem. Período antes do nascer do Sol (= princípio do saber), quando este já ilumina a parte da superfície terrestre ainda na sombra. A claridade rósea que ilumina 0 céu a este, neste período. 0 Oriente. A parte onde nasce o Sol; nascente, leste, este, levante. A qualidade que determina o valor de uma pérola. Luz difusa, precedente ao conhecimento.

\section{A EVOLUĈ̃O DO PENSAMENTO E DA LINGUAGEM}

\section{Análise do conto ficcional "Berom" de John Berryman ${ }^{4}$}

É fundamental contextualizar os reflexos históricos do momento em que 0 autor escreveu este conto ficcional, a fim de olhar por completo 0 short fiction "Berom". Por ser uma ficção, de certo, o conto passa em uma data futura, isto é, como na imaginação, no devaneio de John Berryman (1939) ocorreria a visita de seres de outros planetas à Terra.

A realidade do momento em que "Berom" foi escrito era um pós-guerra (1951), repleto de jogos de poder entre aUnião Soviética e os Estados Unidos - a inesquecível "Guerra Fria". A corrida pelas armas nucleares, pela hegemonia mundial e pelas grandes descobertas subvertia estas duas potências e atormentava a população mundial. Em meio à discussão acompanhada de injúrias e ameaças, bem como de desavenças, Berryman mostra, de forma habilidosa, um suspense futurista diante de uma visita inusitada e da procura por uma forma de comunicação, ou seja, ele utiliza um fato extraordinário para apresentar dois pontos fundamentais: sua opinião sobre a guerra fria e a importância do conhecimento da Palavra para estabelecer uma relação.

Além disso, é possível perceber o claro relacionamento entre evolução tecnológicaeaumento da disputa pela detenção do saber, isto é, este é concebido tal qual uma "arma" valiosíssima para qualquer nação que deseja ser suprema sobre todas as demais. Outrossim, vemos o questionamento entre os valores do patriotismo e os pessoais, quando uma personagem criada pelo autor - Yancey apresenta-se como um dos melhores lingüistas do mundo, o qual é convocado pelas forças militares para auxiliar no intermédio da comunicação e demonstra sua aversão à decisão de não compartilhar esta visita com população científica, tratando 0 descobrimento de algo novo como direito daquele que 0 encontrou primeiro. O bviamente, Berryman aponta sua crítica à corrida bélica instituída entre seu país - Estados Unidos - e a URSS.

Ao longo do conto, podemos atentar para inúmeras situações de semelhança entre os visitantes do outro planeta e o Ser Humano. Escrevem com letras do alfabeto que é familiar, conhecem os números arábicos e "falam" palavras, até certo ponto da estória, incompreensíveis.

\footnotetext{
${ }^{4}$ Citamos algumas informações sobre o autor: John Berryman (1919-1988). John Berryman escreveu short fictions desde seus 20 anos, isto é, contos de ficção e usou em alguns o pseudônimo Walter Bupp. Acredito que écompreensível, afinal, em plena 2a. G uerra Mundial, este jovem publicou três obras: "Special Flight", "Space Rating" e "Beyond the Stars", todos em 1939. Aindanos tempos do conflito bipolar, lançou "Rendezvous" e "The G entle Pirates". O bras: Special Flight (1939); Space Rating (1939); Beyond the Stars (1939); Rendezvous (1940); The G entlePirates (1942); Berom (1951); E quations for D estiny (1952); The Right Time (1963); Stuck (1964); Something To Say (1966); The Big D ish (1986); Assinadas com pseudônimo "Walter Bupp": Vigorish (1960); Card Trick(1961); ModusVivendi(1961); The Trouble with Telestar(1963); Psi for Sale (1965) - Nota da Autora. D isponível em: <www.revista.criterio.nom.br/ delmorealexandre01.htm>. A cesso em: 23 out. 2007.
} 
Há um determinado instante que Yancey utiliza a linguagem corporal para transmitir suas palavras - já que não eram entendidas pelo visitante - logo, ele abraça com carinho aquele Ser e, instintivamente, a sensação de aceitação e demonstração de afeto é estabelecida entre ambos. Sem o uso próprio da palavra. Entretanto, podemos afirmar que tanto Yancey quanto 0 visitante já possuíam em seu logosinterior o signo do abraço e mais ainda o significado deste.

A função primordial da linguagem é a comunicação, intercâmbio social [...] $\mathrm{Na}$ ausência de um sistema de signos, lingǘstico ou não, só é possível o mais primitivo e limitado tipo de comunicação. A comunicação por meio de movimentos expressivos é observada, sobretudo entre osanimais, contudo não é tanto comunicação, mas antes uma difusão de afeto. (VYGOTSKY, 1998, p. 6-7).

É claro que existe um interesse comum em ter uma comunicação estabelecida (caso contrário seria impossível qualquer relacionamento). 0 autor descreve tal intenção, porém o que interessa aos militares é descobrir o conhecimento que o visitante detém e ocultar dos Soviéticos.

D esta forma, para conseguir compreender um ao outro, Yancey começa a traçar um caminho evolutivo para se relacionar. Com muitos gestos, ele demonstra para $\mathrm{G}$ onish - nome do visitante que o lingüista conhece depois de pronunciar diversas vezes o seu e apontar para si - por meio de um relógio o funcionamento das horas paranosso planeta e vice-versa. "Acho que ele entende a maioria de nossos gestos, a nossa linguagem não falada" afirma a personagem.

E, assim, desenvolve-se a comunicação entre ambos. Vale ressaltar que estes momentos de troca de afetos ocorrem com o pano de fundo da pressão entre EUA e URSS, com esta querendo participar do conhecimento de Gonish, já que sua nave apresentava tecnologias extremamente avançadas para 0 interesse militar e político.
As letras escritas e o som emitido pelo visitante - BEROM - são estranhos e desconhecidos. A fim de decifrar, isto é, revelar o sentido para que esta palavra ganhe significado, Yancey pesquisa códigos usados antigamente para transmitir informações sem que fossem facilmente compreendidas, ou seja, observamos aimportância do saber oriundo de experiências anteriores, pois assim se torna plausível encontrar pontos de relação (LURIA, 1986). Neste desenvolvimento, é imprescindível o aprofundamento da compreensão, mergulhar no cognitivo do outro para preencher com o significado que é consoante no egoico. Com a finalidade de dar valor pessoal ao conteúdo vazio apresentado no princípio.

A demais de toda a abordagem lingüísticoevolutiva das relações de comunicação entre Yancey e $\mathrm{G}$ onish, John Berryman envolve o leitor com todo o suspenseem torno do prelúdio eminente de uma guerra catastrófica com armas nucleares e devastação. Este contexto é extremamente decisivo para o desfecho do conto e ainda mais para a crítica do autor frente a sua própria realidade, visto que ele escreveu durante o pós-guerra.

O epílogo de "Berom" apresentaquestões para serem refletidas pelo leitor. Não somente 0 poder que o conhecimento (= logos, palavra, comunicação) confere, mas também a inexistência de uma maturidade política que não seja a barbárie da Guerra Fria e de tantas outras contemporâneas ao século XXI. Acredito que a apreciação minuciosa destas questões permeia nosso cotidiano, o que torna este conto não tanto ficcional quanto nos apresente somente em seu enredo, já que ao analisar seu âmago notamos a familiaridade com o mundo atual em que vivemos. Além disso, é uma sedutora proposta para acompanhar os passos para chegar à capacidade de trocas ideias e discuti-las, tendo como desafio: a própria Palavra, no tocante a sua linguagem e seu pensamento. 
A COMUNICAÇÃO MIDIÁTICA

\author{
Análise do filme "Short Curts" \\ de Robert Altman ${ }^{5}$
}

Cenas da Vida conta, em paralelo, o cotidiano de diversos núcleos familiares ou não, os quais são aproximados ao máximo da representação da vida real (uma das formas envolventes proporcionadas pelo Cinema). Este filme mostra uma comédia dramática com foco nos comportamentos humanos, pois apresenta cenas de diversão e de crítica social (drogas, sexo, traição, abuso, negligência frente a um assassinato). Assim, estes grupos se interagem sem saber desta relação entrelaçada. Logo, em cada atitude que tomam ou palavras que dizem, altera-se por consequiência a "vida" do outro grupo. E, mesmo a mais equilibrada das famílias possui seu "lado negro", demonstrando que todos os grupos possuem certa dependência.

Aceitar as mentiras, ser uma mulher mal amada ou homem que traí e é traído, são as ricas matérias-primas para os enredos das "cenas da vida", como recortes da representação da vida real.

Uma cantora de blues e a sua filha, que é musicista clássica, passam a complexidade da convivência familiar, tendo em vista as mentiras sobre 0 passado e as expectativas que, quando jovens, queremos de nossos pais. A rede de vidas que vão se entrelaçando sem saber que estão neste movimento de interação, oferecendo um rico repertório para o estudo dos comportamentos humanos em sua maioria doentia, isto é, viciada, não só em drogas químicas, mas também nas sociais.

Há partes que demonstram uma brutalidade com a vida considerando-a somente um objeto, contrapondo até mesmo a ideia inicial que parecia valorizar os comportamentos humanos, contudo se percebe que, justamente este descaso com 0 outro, é uma cena da vida. D esta forma, observamos a tendência do diretor em apontar 0 amplo espetro de valores que cada ser humano possui, desta forma, em pequenos recortes do cotidiano daspersonagensforma-se o grandequebracabeça do filme.

Nas cenas finais, ocorre um fato que acaba mexendo com todas as personagens do filme, mesmo assim a importância dada é bastante banal diante da grandeza do acontecimento. Ademais, a televisão tem um papel fundamental neste desfecho, já que apresenta por meio de um noticiário alguns fatos não verdadeiros e até certo ponto distorcidos, provando uma crítica do filme ou um alerta sobre as informações que temos pela TV, porque não devemos validar tudo que recebemos pelos meios de comunicação, afinal nem mesmo nos outros seres humanos podemos confiar plenamente.

Poderiamos dizer, por meio deste filme, que influenciamos na vida do outro e vice-versa (Teoria Sistêmica ${ }^{6}$. A lém de constatar que não ter conhecimento ou fingir que não o tem é se anular enquanto ser crítico, sendo conivente com determinadas atitudes e, destaforma, promovendo a violência psicológica, ou seja, não direta ou física, mas sim no comportamento humano. Formamos assim nossas representações do real fomentando o que nos parece mais conveniente $e$ seguro, demonstrando que não somostão diferentes dos homens de outros tempos mais antigos, isto é, o medo de conhecer certas verdades, que implicam em admitir falhas e encarar os desafios, sempre fez da comodidadealgo natural, como a Lei do Mínimo Esforço, pois é bem mais "confortável" manter a corrupção em nossa Caixa de Pandora.?

\section{CON SIDERAÇÕES FINAIS}

Frente a todos os aspectos analisados em diferentes peças e enredos apresentados neste trabalho, podemos compreender as relações

\footnotetext{
Curiosidades: E sse enredo influenciou Paul Thomas Anderson na concepção da história e formato do filme Magnolia, de 1999. Influências: O s contos de Raymond Carver permearam Short Cuts em formato e ajudaram sua formação. Este autor é celebre em suas estórias e poemas minimalistas. Premiações: O scar Melhor D iretor 1994 e Leão de O uro com Melhor Elenco, assim como G lobo de O uro em 1994 - Nota da Autora. Prysthon, Angela; CARRERO, R. Atalhos na pós-metrópole: acaso, incomunicabilidade e melancolia em três filmes americanos dos anos 90. UFPE. Salvador: Contemporânea, 2004. D isponível em: <http:/ / www.ppgcomufpe.com.br/ arquivos/ PUBLICACA / contemporanea.pdf>. A cesso em: 05 out. 2008.

${ }^{6}$ Segundo a teoria de sistemas, ao invés de se reduzir uma entidade (um animal, p. ex.) para o estudo individual das propriedades de suas partes ou elementos (órgãos ou células), deve-se focalizar no arranjo do todo, ou seja, nas relações entre as partes que seinterconectam einteragem orgânica e estatisticamente.

${ }^{7}$ Caixade Pandoraé uma expressão utilizadaparadesignar qualquer coisa que incitaa curiosidade, mas queé preferível não tocar (como quando se diz que "a curiosidade matou o gato"). Tem origem no mito grego da primeira mulher, Pandora, que por ordem dos deuses abriu um recipiente (há polêmica quanto à natureza deste, talvez uma panela, um jarro, um vaso, ou uma caixa tal como um baú... ) onde se encontravam todos os males que desde então seabateram sobrea humanidade, ficando apenas aquele que destruiria a esperança no fundo do recipiente.
} 
complexas, as quais foram se constituindo no modo de vida do homem, que tem seu nascimento e desenrolar na evolução da palavra, enquanto texto social e habitado por sentidos acrescidos por cada um. O u seja, éuma dupla função que a comunicação exerce: interagir e influenciar, ser ativa e paciente ao mesmo tempo, agir continuamente no processo da sociedade e recontá-lo de formas interpretadas por seus "habitantes".

As palavras são tecidas a partir de uma multidão de fios ideológicos e servem de trama a todas as relaçõessociaisem todososdomínios.É, portanto, claro que a palavra será sempre 0 indicador mais sensível detodasastransformaçõessociais, mesmo aquelas que apenas despontam, que ainda não tomaram forma, que ainda não abriram caminho para sistemas ideológicos estruturados e bem formados. A palavra constitui o meio no qual se produzem lentas acumulações quantitativas de mudanças que ainda não tiveram tempo de engendrar uma formaideológicanova eacabada. A palavra é capaz de registrar as fases transitórias maisíntimas, maisefêmeras dasmudançassociais. (BAKHTIN, 1997, p. 41).

D esta forma, compreendemos a relação homem-objeto do advento imagético em quevivemos, quando os meios de comunicação tornam-se muito mais visuais e utilizam recursos desta natureza para envolver o homem, delegando a ele a compreensão das imagens e diminuindo o uso do verbal.

Por isso, se manifesta a substituição do que era verbal para o visual, como uma derrota do saber diante dos efeitos da participação direta da realidade... 0 que primeiro há que recordaré que a informação visual afeta a personalidade não somente de uma maneira mais intensa, mais considerável e mais profunda, ainda que, sobretudo, de uma maneira diferente, ou seja, segundo outrasmodalidadesqueasdainformação verbal. (COHEN; ROLLAS, 1967, p. 32 - 33).

Assim, observamos o evoluir do momento hominídio para o homem-visual, que articula palavras pormeio deimagens equeas recebe sem compreender o saber que detém, formando uma de sobrevivência primordial para um espetáculo lúdico das mídias. Indubitavel-mente, conseguimos ser sensibilizados pela força que a palavra oferece, como um ato prévio ao de detenção da dominação por meio dela, vimos como de alguns modos ela pode ser essencial para a sobrevivência e, finalmente, seu atual significado, 0 crescimento de interventores ou interpretadores da palavra para "facilitar" e "atingir" mais os homens por linguagens baseadas em imagens, movimento etodo 0 aparato tecnológico em constante desenvolvimento.

\section{REFERÊNCIAS}

SHORT CUTS. Direção: Robert Altman. São Paulo: Playarte, 1993. 1 VHS (187 min.). Criterion Pictures Corp. / PlayArte.

BAK HTIN, Mikhail. Marxismo e filosofia da linguagem. 8. ed. São Paulo: Hucitec, 1997.

COHEN-SEAT, Gilbert; FOUGEY ROLLAS, Pierre. La informácion visual. In: COHENSEAT, Gilbert; FOUGEY RO LLAS, Pierre. La influencia del cine y la televisión. México: Fondo de Cultura, 1967. p. 171-176.

FABRE, Maurice. História da comunicação. 2. ed. Lisboa: Moraes, 1980.

FERRAZ, Maria Cristina. Sociedade tecnológica: de Prometeu a Fausto. Revista Contracampo, v. 4, p. 117-124, 2000.

GOETHE, Johann Wolfgang Von. 0 conto da serpente verde e da linda Lilie. [S.l.]: Landy, 2003.

2001 - UMA ODISSÉIA NO ESPACO. Direção: Stanley Kubrick. Inglaterra: MGM, 1968. 1 DVD (149 min.). p\&b (DVD NBO).

LURIA, Alexander Romanovich. Pensamento e linguagem: as últimas conferências de Luria. Porto Alegre: Artes Médicas, 1986.

PRY STHO N, Angela; CARRERO, Rodrigo. Atalhos na pós-metrópole: acaso, incomunicabilidade e melancolia em três filmes americanos dos anos 90. UFPE. Salvador: Contemporânea, 2004. D isponível em: <http:/ / www.ppgcomufpe.com.br/ arquivos/ PUBLICACAO/ contemporanea.pdf>. A cesso em 05 out. 2008.

VIG OT SKY, Lev Semenovich. Pensamento e linguagem. São Paulo: Martins Fontes, 1998.

Recebido: 09/ 10/ 2008

Received: 10/ 09/2008

Aprovado: 31/ 10/ 2008

A pproved: 10/31/ 2008 